\title{
ПЛАНИРОВАНИЕ ОСВОЕНИЯ НЕФТЯНЫХ ЗАПАСОВ В УСЛОВИЯХ ДЕФИЦИТА ФИНАНСОВЫХ РЕСУРСОВ
}

\author{
(c) 2020 Лебедев Алексей Сергеевич \\ Тюменский индустриальный университет, Россия, Тюмень \\ E-mail: dacent.tmn@gmail.com
}

Рассмотрена проблема планирования освоения нефтяных запасов в условиях ограничения финансовых ресурсов. Предложен подход, основанный не на отборе проектов, а на рациональном их распределении во времени. Реализация метода позволяет разработать все месторождения с учетом финансовых возможностей предприятия.

Ключевые слова: инвестиции, планирование, экономическая эффективность, разработка месторождений, нефтяные запасы, финансовые ресурсы.

Освоение нефтяных запасов требует осуществления значительных капитальных вложений. В то же время реальная величина необходимых денежных средств уменьшается за счет доходов проекта и соответствует показателю потребности в дополнительном финансировании. Он определяется, как абсолютная величина отрицательного накопленного потока наличности проекта.

Методы управления потребностью в дополнительном финансировании (ПДФ) [1, 3] портфеля инвестиционных проектов путём отбора оптимальной его части достаточно хорошо разработаны [4, 6]. Однако принципы рационального природопользования и непрерывности процесса освоения недр, установленные Федеральным законом «О недрах» не всегда позволяют отбирать проекты только по экономическим критериям [2]. Инвестиционную емкость портфеля можно уменьшить путём отсрочки реализации одних проектов до периода, более благоприятного с точки зрения использования финансовых результатов других.

Для эффективной реализации предложенного подхода требуется сформировать оптимальный план освоения нефтяных запасов. План должен обеспечить достижение целевого результата при определённых условиях и ограничениях: целевой результат реализации портфеля проектов - получение максимального абсолютного финансового эффекта в рассматриваемом периоде; с технологической точки зрения приоритетность проектов считается равнозначной; каждый инвестиционный проект представляет собой единый комплекс технологических ме- роприятий, следовательно, неделим; основное ограничение - предельная величина финансовых ресурсов определена, доступна и однородна в любой момент времени; проекты между собой абсолютно не взаимосвязаны.

Приведённые положения не являются абсолютными, а лишь ситуационно приняты для данной конкретной задачи. Условия могут быть более сложными, при этом усложняется решение задачи, изменяется число параметров и т.д., но принципиальная основа проблемы и её решения остаётся неизменной.

Для решения поставленной задачи, с учётом всех условий и ограничений, разработана экономико-математическая модель управления освоением нефтяных запасов.

В качестве целевого результата оптимизации параметров модели предлагается достижение максимального значения чистого дисконтированного дохода (1):

$$
N P V_{N}=\sum_{t=1}^{T} \frac{\sum_{i=1}^{N} \Phi_{i}^{M}(t)}{(1+E)^{t}} \rightarrow \max ,
$$

$N P V_{N}$ - чистый дисконтированный доход комплекса проектов освоения нефтяных запасов $[1,3,5,7]$;

$t$ - временной период реализации проектов;

$T$ - общий срок осуществления портфеля проектов;

$E$ - норма дисконта;

$\Phi_{i}^{M}(t)$ - функция потока денежной наличности $i$-го проекта, модифицированная путём варьирования временным интервалом его включе- 
ния в портфель. Формализовано модификацию можно представить следующим образом (2):

$$
\Phi_{i}^{M}(t)=\left\{\begin{array}{l}
\Phi_{i}^{5}(t) ; 0 \leq t \leq \tau_{i} \\
\Phi_{i}\left(t-\tau_{i}\right) ; t>\tau_{i}
\end{array}\right.
$$

где $\Phi_{i}^{M}\left(t-\tau_{i}\right)$ - эмпирическая функция $i$-го потока денежной наличности от периода реализации инвестиционного проекта;

$\Phi_{i}^{E}$ - поток наличности базового варианта (без инвестиций) $i$-го проекта;

$\tau_{i}-$ искомый период ожидания $i$-го проекта инвестиций до начала его осуществления.

Механизм модификации функции для $i$-го проекта действует следующим образом. Допустим некий год $t$ реализации портфеля проектов меньше периода ожидания $\left(\tau_{i}\right)$ определяемого для $i$-го проекта, т.е. его следует финансировать несколько позже. Тогда в данный год модифицированный текущий денежный поток по данному проекту будет соответствовать текущему денежному потоку по базовому варианту освоения этого месторождения (варианту «без инвестиций»). С момента когда период реализации портфеля $(t)$ превысит период ожидания проекта $\left(\tau_{i}\right)$ модифицированный денежный поток по этому проекту начнет соответствовать денежному потоку по данному проекту, т.е. на величину $\tau_{i}$ проект $i$ сдвигается вперед во времени.

Основными ограничениями модели являются значения ПДФ портфеля проектов и объема добычи нефти по группе месторождений, вво- димых в соответствии с данными проектами:

$$
\mid\left(\sum_{i=1}^{T} \frac{\sum_{i=1}^{N} \Phi_{i}^{M}(t)}{(1+E)^{t}}\right)_{(<0)} \leq \Pi Д \Phi_{\text {max }} ; \sum_{i=1}^{N} Q_{H i t} \geq Q_{H t},
$$

где ПДФ $\Phi_{L I M}-$ объем инвестиционных ресурсов, который может привлечь инвестор для реализации портфеля, ден. ед.;

$Q_{\text {Hit }}$ - годовой объем добычи нефти по $i$-му месторождению, млн. т;

$Q_{H t}-$ необходимый объем годовой добычи нефти, млн. т.

В процессе поиска параметров модели должны соблюдаться также дополнительные условия:

$$
\begin{aligned}
& {[\tau, t, i] } \in[1,2 . . n], \\
& \tau_{i}<\tau^{\max },
\end{aligned}
$$

где $\tau$ max - предельное значение периода ожидания, дольше которого отсрочка реализации проектов не целесообразна;

$n$ - множество натуральных чисел.

В процессе решения предложенной модели требуется найти такие значения периода ожидания каждого проекта $\left(\tau_{i}\right)$, которые обеспечивают достижение максимального целевого результата (NPV) при условии соблюдения всех ограничений (рис. 1).

Методическая сложность формирования финансовых результатов проекта не представляет возможности приведения оптимизационной модели к каноническому виду задачи матема-

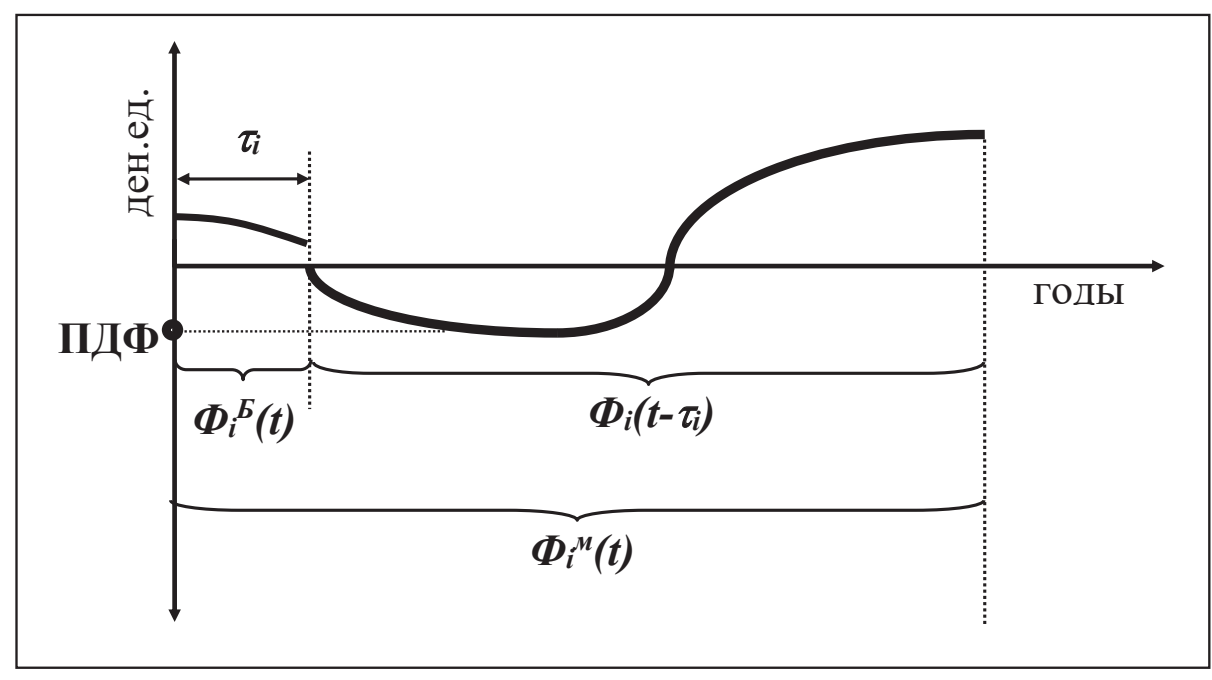

Рис.1. Графическая интерпретация параметров модели 
тического программирования. Поэтому разработан алгоритм поиска временных параметров “ожидания” путём подбора (рис. 2).

Предложенная схема не содержит формальной логики присущей информационновычислительным конструкциям. Она отражает общий смысл, последовательность и условия реализации механизма подбора.

Алгоритм предполагает проведение большого числа итераций и расчётов. Для его практического применения на базе представленной схемы создан программный модуль в среде Microsoft Excel, Visual Basic. Продукт позволяет решать подобные задачи при относительно небольших затратах времени аналитика.

Разработанный набор расчётно-аналитических инструментов апробирован на примере четырёх месторождений Западно-Сибирского региона. На рисунке 3 представлены, годовые потоки наличности проектов до применения опи- санного механизма. При одновременном вводе в эксплуатацию месторождений потребность в дополнительном финансировании составляет 6 миллиардов рублей. Недропользователь может инвестировать не более 1,1 миллиарда рублей. Использован предложенный механизм для планирования портфеля проектов с учётом финансовых возможностей предприятия. Годовые потоки наличности проектов после применения данного подхода представлены на рисунке 4.

Как показано на графиках, освоение 1 и 3 месторождений начинается с первого года. Второй проект должен вводится в четвёртом году, а четвёртый в пятом.

В результате такой последовательности внедрения экономические показатели портфеля значительно изменятся. На рисунке 5 видно, что потребность в дополнительном финансировании уменьшится почти в 6 раз и составит 1080 миллионов рублей.

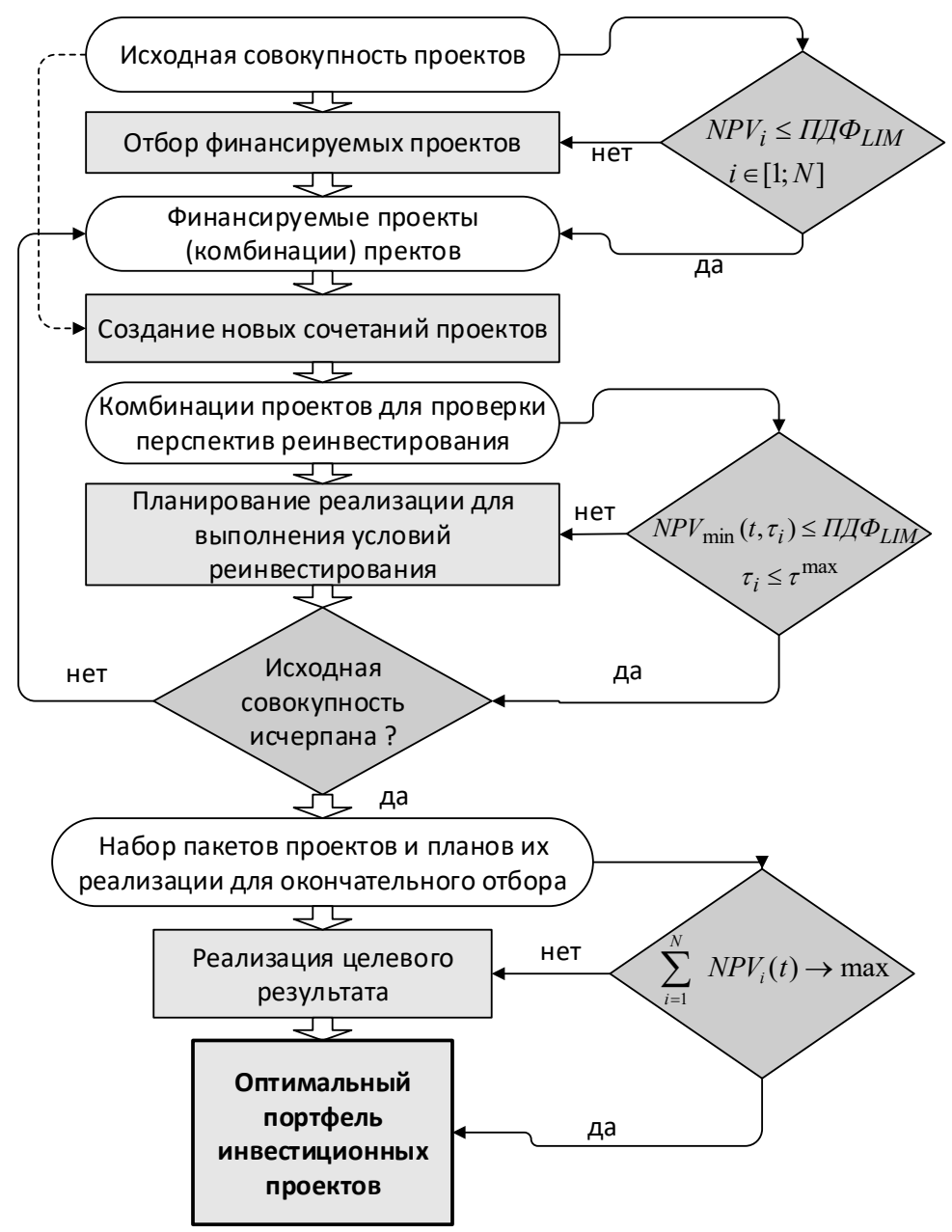

Puc. 2. Алгоритм формирования оптимального портфеля проектов в условиях ограничения финансовых ресурсов 


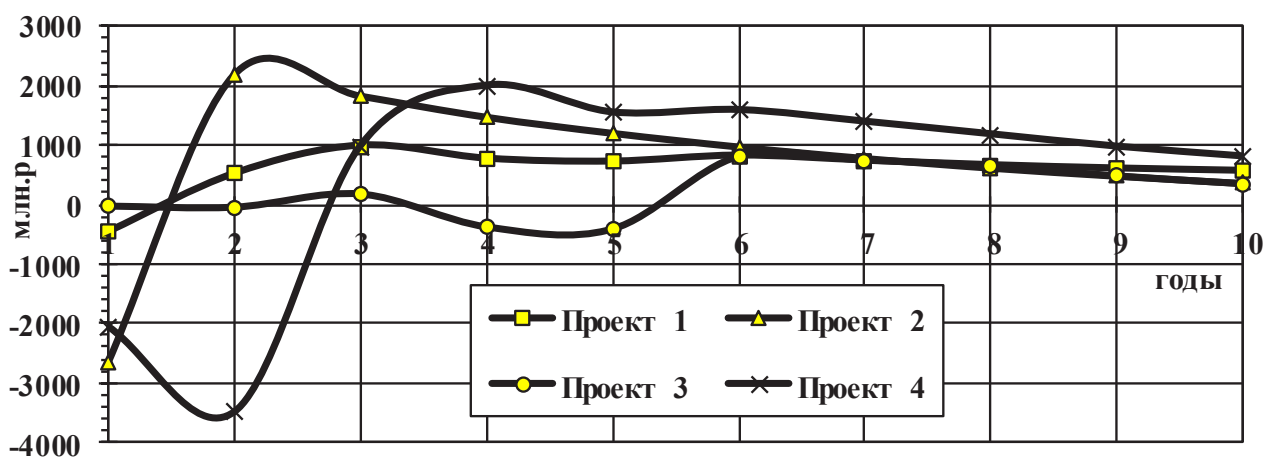

Рис.3. Годовые потоки наличности проектов до планирования

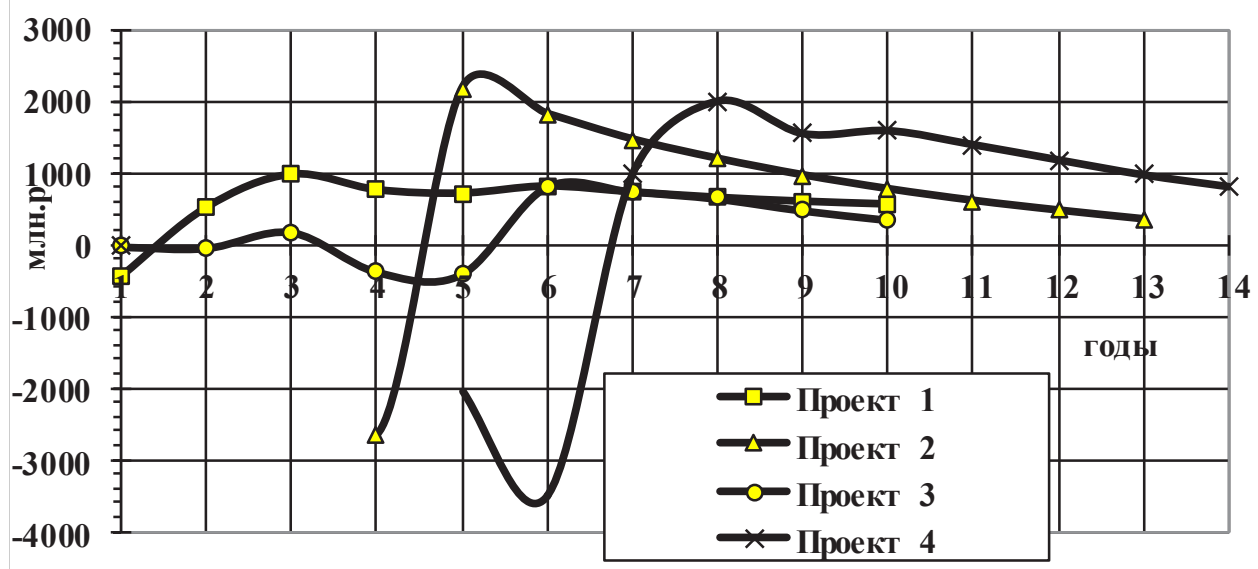

Рис.4. Годовые потоки наличности проектов после планирования

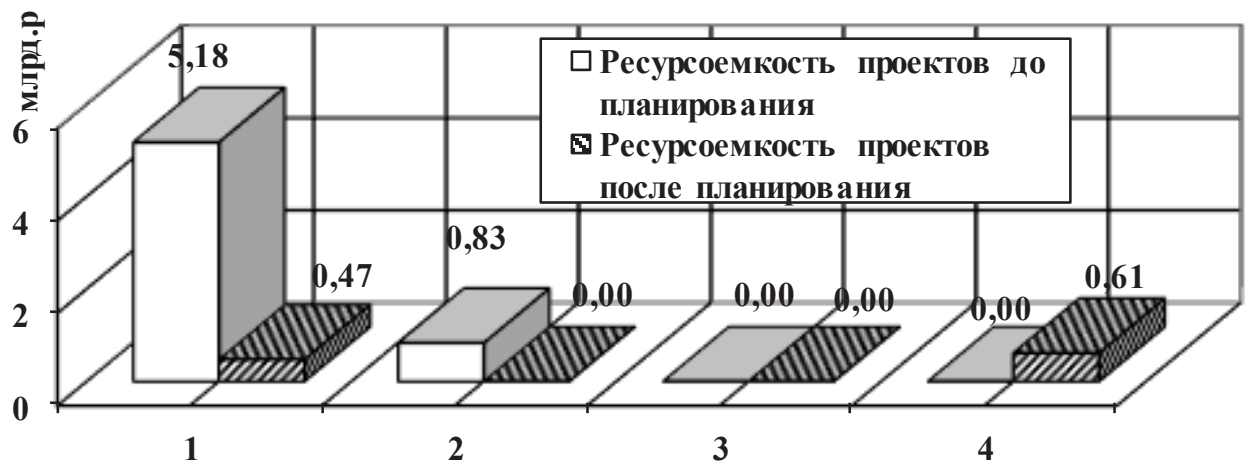

Рис.5. Динамика потребности в дополнительном финансировании до и после использования предлагаемого механизма планирования

Такая величина потребности в дополнительном финансировании не превышает финансовых возможностей предприятия.

Таким образом, особенности нефтедобывающей отрасли не всегда позволяют применять традиционные инструменты управления проектами. Так, их отбор зачастую не приемлем из-за непрерывности технологических процессов освоения недр. Между тем возможен другой подход к инвестиционному бюджетированию. Можно внедрять одни проекты несколько позже и за счет финансовых результатов других. Подход потребовал создания специальных технологий. Предложены экономико-математическая модель и алгоритм ее решения, позволяющие сформировать оптимальный набор проектов и в то же время план их осуществления, учитывающий финансовые возможности предприятия. 


\section{Библиографический список}

1. Виленский П.Л., ЛивщицВ.Н., Смоляк С.А. Оценка эффективности инвестиционных проектов: Теория и практика: Учеб.пособие. - 5 изд., перераб. и доп.- М.: Поли Принт Сервис, 2015. - 1300 с.

2. Закон Российской Федерации от 21 февраля 1992 г. № 2395-I «О недрах».

3. Коссов В.В., Лившиц В.Н., Шахназаров А. Г. Методические рекомендации по оценке эффективности инвестиционных проектов.- М.: Экономика, 2000.

4. Лебедев А.С., Новоселов С.В., ПленкинаВ.В. Экономико-математическое моделирование освоения нефтяных запасов в условиях действующих финансовых ограничений / Научные труды V Международной научно-практической конференции «Фундаментальные и прикладные проблемы приборостроения, информатики, экономики и права».- М.: МГАПИ, 2002.

5. Липсиц, И.В. Инвестиционный анализ. Подготовка и оценка инвестиций в реальные активы: Учебник / И. В. Липсиц, В. В. Коссов.- М.: Инфра-М, 2017.- 320 с.

6. Осиновская И.В., Пермяков А. С., Лебедев А. С., Пленкина М.В. Инвестирование: Учебное пособие.- Тюмень: ТюмГНГУ, 2013.

7. Экономическая оценка инвестиций: Учебник / Под ред. Римера М.И..- СПб.: Питер, 2017. - 16 с. 